\title{
Raising and control
}

\section{Citation}

Polinsky Maria. 2013. "Raising and control." In The Cambridge Handbook of Generative Syntax: Grammar and Syntax, ed. Marcel den Dikken, 577-606. Cambridge: Cambridge University Press. doi:10.1017/cbo9780511804571.021

\section{Published Version}

doi:10.1017/cbo9780511804571.021

\section{Permanent link}

http://nrs.harvard.edu/urn-3:HUL.InstRepos:37108755

\section{Terms of Use}

This article was downloaded from Harvard University's DASH repository, and is made available under the terms and conditions applicable to Open Access Policy Articles, as set forth at http:// nrs.harvard.edu/urn-3:HUL.InstRepos:dash.current.terms-of-use\#OAP

\section{Share Your Story}

The Harvard community has made this article openly available.

Please share how this access benefits you. Submit a story.

Accessibility 


\section{Raising and control ${ }^{*}$}

Maria Polinsky

Harvard University

Compare the following two sentences:

(1) The police appeared to the protesters [__ to stay calm]

(2) The police appealed to the protesters [__ to stay calm]

On paper, they differ in one symbol, but semantically and structurally they show interesting similarities and differences. Both involve an obligatory interpretational dependency between an overt argument NP in the matrix clause and a lower unpronounced argument in the complement clause, represented atheoretically as a gap. However, in (1) the missing subject of the infinitival clause is the same as the subject of the matrix (the police), and in (2) it is the object of the main clause (the protesters). The difference between these two constructions is an instance of the well-known distinction between raising (1) and control (2), two phenomena that have been at the forefront of linguistic theory starting with Rosenbaum 1967, Postal 1970, 1974, Jackendoff 1972: Ch. 2, Chomsky 1973, Bach 1979, and Bresnan 1972, 1982. This chapter will examine these phenomena and survey the basic approaches to them in linguistic theory. Given the prominence of raising and control in linguistic literature it is impossible to do justice to all the rich work on their syntax-the reader should view this chapter as an introduction to the existing approaches and is advised to consider further readings presented at the end of the chapter.

The chapter is structured as follows: In section 1, we will survey the basic properties of raising and control structures. Section 2 presents the current

* I am grateful to Youssef Haddad, Eric Potsdam, Greg Scontras, and Barbara Stiebels for helpful discussions of this work. I owe my deepest gratitude to Marcel den Dikken for his thorough and thought provoking comments on an earlier version of this work. Whatever errors and omissions are left in this chapter is entirely my responsibility. 
minimalist views on raising and control. Section 3 shows the main approaches to raising and control in unification-based lexicalist theories. Section 4 uses the material from previous sections to deliberate on the inventory of silent categories employed in modern syntactic theories. Section 5 outlines some remaining issues in the syntax of raising and control and presents further directions that stem from the main issues discussed in this chapter.

\section{Basic properties of raising and control constructions.}

\subsection{Raising to subject}

Raising is somewhat limited by lexical idiosyncrasies of a given language; in English it is possible with predicates like seem, appear, happen, be likely, be apt, turn out, begin but not similar predicates like be possible (see Davies and Dubinsky 2004: Ch.1 for a list of typical raising predicates). Cross-linguistically, the set of lexical items that license raising must be systematically determined in each case, as it may vary from language to language in semi-predictable ways. Nevertheless, it is time and again the case that similar lexical items can be used as raising and control predicates across languages; for instance, modal and aspectual verbs are often raising predicates, and verbs of intention and desire are typical control predicates (Stiebels 2007, 2010). Furthermore, an interesting generalization about raising and control has to do with the fact that one and the same lexical item can alternately participate in raising and control. Thus, as we will see below, begin is sometimes a raising predicate and sometimes a control predicate. These empirical facts cast some doubt on the prospects of a straightforward lexical classification of words/predicates in terms of raising $v s$. control.

Returning to our example (1), this construction can alternate with the construction that has the expletive subject it:
a. The police appeared to the protesters [__ to stay calm]
b. It appeared to the protesters that the police stayed calm 
The co-occurrence with the expletive (as well as with idiom chunks, cf. (4) and (11) below, where a raising-to-object verb appears) is an indication that raising verbs do not assign an external theta role to their argument, thus patterning just like other unaccusative verbs. ${ }^{1}$ The only difference between raising verbs and unaccusatives such as fall or arrive is that the latter take a DP complement, whereas raising verbs take a clausal complement (we will discuss the actual category of that complement in section 2).

(4) The cat appears to be out of the bag

The DP that can undergo raising (the police in our example) is interpreted with the lower predicate. The position of that DP is relevant for anaphoric relations; compare the difference in binding between (5a) where the silent subject of the infinitive determines the place and interpretation of the reciprocal, and (5b), where the reciprocal is bound by the matrix subject:

(5) a. Bruce Wayne and Batman seemed to Vicki Vale [___i to hate each other $\left.r_{i}\right]$

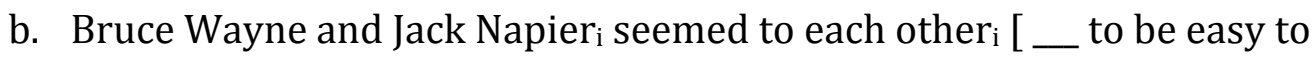
defeat]

Another empirical generalization is that the subject-to-subject raising construction is scopally ambiguous. Thus, the sentence in (5) has two readings:

(6) Someone from Chicago is likely to win a Nobel Prize

i. There is someone in Chicago who is likely to win a Nobel Prize (someone scopes over likely)

${ }^{1}$ Some researchers (Bennis 1986, Moro 1997) disagree with the characterization of the proleptic it as a true expletive and consider it more of an argument. A reader who shares their concerns may be more convinced by the behavior of idiom chunks (4), (11) and the expletive there (21). 
ii. It is likely that there is someone from Chicago who will win a Nobel Prize (likely scopes over someone)

The interpretation in (5-ii) is only possible if someone is implicitly present in the downstairs infinitival clause, and is accessible there for scope calculation. Note that there is no ambiguity if the indefinite expression cannot be interpreted as the implicit subject of the infinitival clause:

(7) Milton Friedman seemed to someone from Chicago to be a Nobel Prize winner (scopally unambiguous with respect to seem and someone)

Finally, raising cannot skip intermediate clauses and has to create a dependency between the subject of an embedded clause and the subject of the immediately dominating clause:

(8) * $\mathrm{Kim}_{\mathrm{i}}$ seemed [for Pat to believe [__i to know the answer]]

To summarize our empirical observations, raising to subject has the following properties:

(9) a. it targets only the subject of embedded clauses

b. it cannot skip clauses

c. it shows a lack of selectional restrictions (idiom chunks can raise, and there is no imperative formation)

d. it exhibits reconstruction for binding and scope

\subsection{Raising to object}

Consider now the pair in (10):

(10) a. Everyone expected that Argentina would win the World Cup

b. Everyone expected Argentina to win the World Cup 
The DP Argentina is clearly the subject of the embedded clause in (10a) but it can also appear as the object of the matrix verb (10b). In both cases, however, its thematic interpretation comes from the predicate of the embedded, not matrix clause. Just as with raising to subject, the matrix verb does not impose selectional restrictions on the relevant DP-thus, idiom chunks can raise:

(11) Who would expect the pot to be calling the kettle black in this case?

Only subjects of the embedded clause can undergo raising to object, just as was the case with raising to subject.

Although semantically the DP in the raising to object construction is interpreted with the embedded verb, structurally it behaves as if it is in the matrix clause-for instance, it can be the subject of the passive featuring the matrix verb, as in (12).

(12) Argentina was expected (by everyone) to win the World Cup

Furthermore, the raised object can be separated from the infinitival clause by the intervening material, which clearly belongs with the matrix clause, e.g., ${ }^{2}$

(13) a. The chairman expected his earnings foolishly to show increases b. She made Jerry out to be famous

For the adverbial foolishly to be interpreted with the matrix verb (which is the only interpretation that makes sense) it has to be in the same clause as that verb; this means that the material preceding it, including the raised DP, should also belong with the matrix clause. Likewise, the particle verb make out has to be represented in

\footnotetext{
${ }^{2}$ For further discussion of this phenomenon, see Postal (1974), Johnson (1991), Ernst (2002), Runner (2006).
} 
the same clause, therefore the DP separating the verb and the particle is also in that clause.

However, there is also contradictory empirical evidence, which is unexpected under the conception that the raised DP belongs in the matrix clause. Compare the following contrast (see Chomsky 1973, Postal 1974, Runner 1998 for an extensive discussion):

(14) a. Which artist do you admire [paintings by __ _ ] ?

b. ?/*Which artist $t_{i}$ do you expect [paintings by ___ ] to sell the best?

Subextraction out of a regular object in (14a) is unproblematic, but subextraction out of the raised object in (14b) is marginal at best, and many native speakers reject this extraction altogether. This contrast is startling if both clauses have the same syntactic structure and differ only in complexity. Worse still, regular objects can always participate in tough-movement, illustrated in (15b), but raised objects cannot (16b) (Chomsky 1973: 254; Postal 1974; Langacker 1995; Runner 2006):

(15) a. It was easy for Jones to force Smith to leave

b. Smith was easy for Jones to force to leave

(16) a. It was easy for Jones to expect Smith to leave

b. *Smith was easy for Jones to expect to leave

Assuming that tough-movement should take any object and transform it into a subject, these facts are startling, and the judgments on the offending sentences are even more robust than in the case of subextraction. Altogether, there seems to be interesting evidence that the subject of the infinitival clause raises to the object of the matrix clause, but there are also contradictory data suggesting that the raised object is somehow different from its more typical counterpart.

\subsection{Control: Subject and object control}


Just as raising involves an interpretational dependency between an overt, fully lexically specified DP in one clause and a silent (missing) argument of another clause, so does control, ${ }^{3}$ as illustrated in (17) for subject and (18) for object control:

(17) The police intended to stay calm

(18) The police appealed to the protesters to stay calm

In (16), the subject of intending and the implicit subject of the infinitival clause to stay calm have the same denotation: the police; this is an instance of subject control, which can be compared to subject to subject raising discussed above. In (18), the object of the matrix clause (the protesters) identifies the implicit subject of the infinitival clause; this is an instance of object control, again comparable, at least at first blush, with raising to object introduced above.

Like raising, control can only apply to subjects of embedded clauses, and like raising, it can create an interpretive dependency between the embedded subject and matrix subject or matrix object. It also obeys locality-no intermediate clauses can occur between the matrix and the embedded control clause.

Control and raising have several principal differences, however. First, they differ with respect to passivization. If the embedded clause of the raising construction is passive, it is truth conditionally equivalent to the active infinitival clause (19); under control, there is no such equivalence: (20a) denotes a different state of affairs than (20b):

(19) a. The public expected the players to hug Maradona = b. The public expected Maradona to be hugged by the players

(20) a. The public implored the players to hug Maradona $\neq$ b. The public implored Maradona to be hugged by the players

${ }^{3}$ Also known as Equi(-NP-Deletion) in the earlier generative literature. 
Second, control predicates impose selectional restrictions on their arguments, which means that expletives or idiom chunks cannot participate in control chains, cf. the contrast between (21) and (22):

(21) There is likely to be a riot

(22) *There decided to be a riot

In an extension of selectional restrictions, control arguments typically have to be sentient and volitional:

(23) The governor decided to withdraw the resources from the program

(24) *The crisis decided to withdraw the resources from the program

Unlike raising, control constructions do not show evidence of reconstruction; the only reading of (25) is that there is a particular individual who decided to run the race, thus someone takes wide scope:

(25) Someone decided to run the race

Next, raising and control constructions differ in their ability to nominalize: nominalizations of raising constructions are impossible, whereas control structures nominalize freely, thus:

(26) a. *the police's appearance (to the protesters) to stay calm

b. *Kim's consideration of Pat to be a good role model

a. the police's intention to stay calm

b. the police's appeal to the protesters to remain calm

Next, control, unlike raising, allows for differences in interpretation depending on the uniqueness of the controller, i.e., the degree to which the missing argument in the referential dependency has to be identified with the overt argument in that 
dependency (Jackendoff and Culicover 2003). For instance, the subject of the infinitive has to be identified with the object of the matrix clause in (28), may be partially identified with it in (29), and cannot be identified with it at all in (30):4

(28) The author decided [[ __i to withdraw the paper]

(29) The chairman $n_{i}$ agreed [ _ _ ${ }_{i+k}$ to meet tomorrow]

(30) It is not recommended [ _ " "anyone" to swim here]

Some researchers view the distinction between unique and non-unique control (variable control) as a continuum; the position on that continuum is determined by the semantic properties of a particular control verb and the overall event structure of the relevant construction. Such a position is particularly well articulated by Culicover and Jackendoff in a series of papers (Culicover and Jackendoff 2001; Jackendoff and Culicover 2003) and their book "Simpler Syntax" (2005). Other researchers view the distinction as categorical-it can be couched in terms of obligatory and non-obligatory control, cf. for example, Williams (1980), Chomsky and Lasnik (1993), Hornstein $(2001,2003)$, among others. Generally, there are two main requirements on obligatory control: uniqueness of the controller and locality of the relation between the controller and the controlee. The uniqueness can be derived either from the lexical properties of a given control predicate (which seems to be the predominant view in the literature, cf. Stiebels 2010) or in a purely syntactic way, as will be shown in section 2.3 below.

Related to the phenomenon of variable control is the phenomenon of control shift (Růžička 1983, 1999, Comrie 1984, 1985, Farkas 1988, Wegener 1989, Sag \& Pollard 1991, Panther 1993, Petter 1998, Stiebels 2007, 2010): control predicates that take at least three arguments (including the clausal complement) shifts from subject to object control or vice versa. Control shift is better illustrated in German than in English; for instance, versprechen 'promise' allows shift from subject to

\footnotetext{
${ }^{4}$ Partial control and non-obligatory control do not have ungrammatical counterparts in the realm of raising constructions (see also Landau 2001).
} 
object control, bitten 'ask', shift in the opposite direction, cf.:

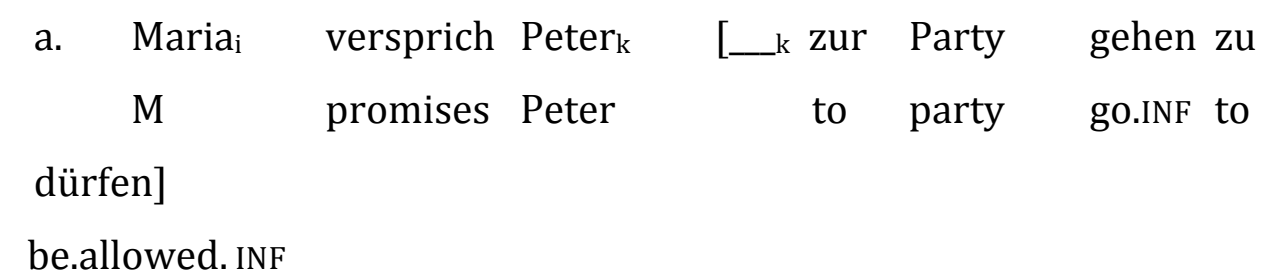

'Mary promises Peter to be allowed to go to the party.'

$\begin{array}{lllll}\text { b. Maria bat } & \text { Peter }_{\mathrm{k}}[\ldots \text { i zur Party } & \text { gehen } & \mathrm{zu} \\ \mathrm{M} \text { asked } & \text { Peter to party } & \text { go.INF } & \text { to } \\ \text { dürfen }] & & & & \\ \text { be.allowed. INF } & & & \\ \end{array}$

'Mary asked Peter to be allowed to go to the party.'

Unlike control, raising constructions do not allow for shift or variable antecedents of the silent element of the dependency-compare the German examples in (31) with their raising counterpart (and its English translation) where no shift from the subject to object is ever possible (see also (7) above). ${ }^{5}$

\footnotetext{
${ }^{5}$ It has on occasion been pointed out that control shift is not a property of control as such because it can be mimicked in finite contexts, with overt pronominal subjects. Thus, (i) is matched by (ii) and (iii), by (iv):

(i) John promised Mary to leave

(ii) John promised Mary that he would leave

(iii) John promised Mary to be allowed to leave

(iv) John promised Mary that she would be allowed to leave.
}

The parallel is further supported by the fact that in both infinitival and in finite clauses be allowed to shifts back to subject control if an adjunct is added to the lower clause that makes the subject a more natural antecedent: 


$\begin{array}{lccccc}\text { Maria }_{i} & \text { schien } & \text { Peter[__i } & \text { zur Party } & \text { gehen } \\ \text { M } & \text { seemed } & \text { Peter to party go.INF } & \\ \text { zu } & \text { dürfen] } & & & & \\ \text { to } & \text { be.allowed. INF } & & & \end{array}$

'Mary seemed to Peter to be allowed to go to the party.'

In another principled difference, object control allows subextraction, while subject to object raising does not-compare (14b), repeated below, and (33a, b): 6

b.?/*Which artist ${ }_{i}$ do you expect [paintings by __ ${ }_{i}$ ] to sell the best?

(33) a. Which senator did she persuade the staff of to give her an internship?

b. *Which senator did she expect that staff of to give her an internship?

Given interesting similarities and differences between raising and control, one of the crucial questions addressed by syntactic theories is whether the similarities outweigh the differences and the two constructions should receive a unified

(v) John (talking on the phone to Mary about the fact that he would once again have to work late) promised her to be allowed to leave once he had read all of the documents on his desk

(vi) John (talking on the phone to Mary about the fact that he would once again have to work late) promised her that he would be allowed to leave once he had read all of the documents on his desk

This last point actually suggests that the fluidity of antecedent choice seems to be largely determined by pragmatics/context or world knowledge. If so, control shift may not need to be accounted for in syntax.

${ }^{6}$ See Runner 2006 for further discussion and references therein. 
syntactic account. ${ }^{7}$ This question has been resolved differently in different theoretical frameworks, and the next two sections present a brief overview of the main conceptual arguments to the two phenomena as well as a brief sketch of the respective theoretical models.

\section{Raising and control in generative grammar}

The account of subject raising in formal grammars is probably the most straightforward in and has undergone little change since the seminal work by Rosenbaum (1967). The main idea is that the structure consists of two clauses, the matrix and the infinitival clause, which is a TP. ${ }^{8}$

The subject DP of the embedded clause moves from the argument position in which it receives an interpretation to a non-theta-position. This movement is necessitated by the EPP of the matrix clause, thus:

a. $\left[\operatorname{TP}_{\mathrm{D}}[\mathrm{DP}\right.$ e]seem/appear/be likely $\quad$ [тр Bruce Wayne to defeat Jack Napier] ]

b. [тр [рт Bruce Wayne $e_{i}$ [vр seem/appear/be likely [тр Bruce Wayne ${ }_{i}$ to defeat Jack Napier] ]

\footnotetext{
${ }^{7}$ Another large question addressed by researchers has to do with the need to account for these constructions primarily in semantic terms or primarily in structural terms. We will not be concerned with the former option here, but an interested reader may consult the work by Farkas (1988), Růžička (1999), Culicover and Jackendoff (2003), and Stiebels $(2007,2010)$, who address control phenomena primarily in semantic terms. See also fn. 5 above.
}

${ }^{8}$ Some researchers, however, propose that the raising complement may be larger, a CP (Karimi 2008). This would be consistent with the conception that the features of $\mathrm{T}$ are entirely derivative of C's features, hence TP should be unable to exist in the absence of a local C (cf. Chomsky 2008). 


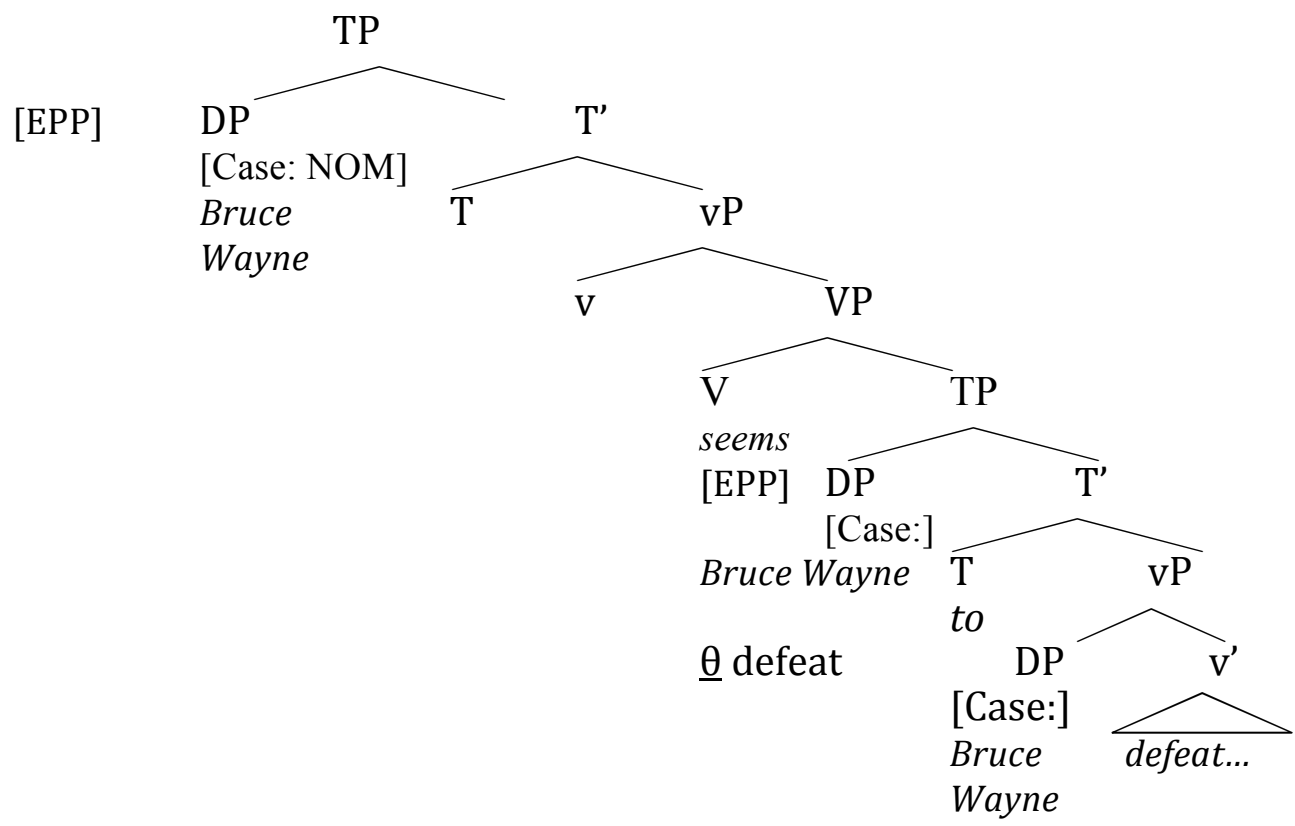

In this derivation, the DP Bruce Wayne first merges in the specifier of the embedded $\mathrm{vP}$, satisfying the external theta-role of the verb defeat. It then moves to the embedded spec,T to satisfy its EPP requirement. Infinitival $\mathrm{T}$ heads are unable to check case, so the case feature of this DP still remains unchecked; it then moves to the specifier of the matrix $\mathrm{T}$, where it receives Case and satisfies the EPP requirement of the matrix clause. ${ }^{9}$

As we have seen in section 1, the higher verb does not select for its external argument. This argument undergoes A-movement from the complement clause. Evidence in support of such movement from the embedded to the matrix position comes from binding and connectivity effects (reconstruction), cf. examples (5) and (6) above. The understanding of the mechanism of movement has undergone changes over the history of generative approaches. In the Principles and Parameters framework, the moved element was represented by an NP-trace. The Minimalist

\footnotetext{
${ }^{9}$ Another possibility of course is that movement to the spec,T position of the infinitival clause does not take place at all (cf. Baltin 1995; Wurmbrand 2007). The overall derivation presented here does not change significantly if that specifier position is skipped.
} 
program (Chomsky 1995, 2000, Nunes 1995) has returned to an old view (as presented in Chomsky 1955/1975) that movement (internal merge) consists of two distinct operations, a copying of the item being displaced and a second, deletion operation that eliminates some copies.

This copy-and-delete approach to movement is particularly relevant in the case of inverse (backward) raising, where the lower, not the higher copy of a movement chain is pronounced. Such raising has been attested at least in some languages (Haddad 2010; Potsdam and Polinsky 2012). We will return to the backward pattern in section 2.3, but here it is crucial to note that its analysis would be difficult without the copy and delete approach to movement.

The crucial components of the syntax of raising are therefore as follows:

(36) a. the construction is biclausal with the embedded TP

b. the higher verb does not assign a theta-role to its external argument

c. the subject DP undergoes raising to satisfy the EPP on the matrix verb

\subsection{Control: PRO}

Like raising, control structures are biclausal, but the standard assumption about control structures is that the embedded clause is larger than in raising-it is typically assumed to be a CP. Some attempts have been made to argue that it is actually smaller (for example, Ghomeshi 2001, Wurmbrand 2001, and the lexicalist analyses discussed in section 3 below). However, care should be taken to distinguish control from restructuring, which involves much smaller complements (Rizzi 1978, 1982; Wurmbrand 2001, among many others). ${ }^{10}$

The most well established approach to control was developed within the Principles and Parameters framework (Chomsky and Lasnik 1993). In this

10 The idea that control complements are VPs (thus, small) was prominent in the more semantically oriented approaches (Bach 1979, Chierchia 1984, Dowty 1985) and is still present in lexicalist theories, which will be discussed in section 3 . 
approach, the unpronounced silent element in control structures is the basegenerated empty category PRO:

(37) The police tried $_{\text {[PRO }}$ to uphold the rules]

Theta Theory forces the presence of PRO in the complement subject position. The Theta Criterion in (38) requires bi-uniqueness between arguments and theta-roles. As a result, every argument position must be filled at deep structure, prior to any transformational operations.

(38) Theta Criterion (Chomsky 1981)

a. each argument bears exactly one theta-role

b. each theta-role is assigned to exactly one argument

With respect to the Control structure in (37), the two agent theta-roles of try and uphold must each be assigned to distinct arguments, the overt DP and PRO, respectively. PRO's presence in the embedded clause's subject position is independently required by the Extended Projection Principle, which stipulates that all clauses must have subjects (Chomsky 1982).

Case Theory then restricts PRO's distribution (Manzini 1983, Koster 1984, Huang 1989, Martin 2001). PRO only appears in the subject position of some infinitives and does not alternate with an overt noun phrase. In some earlier analyses, it was assumed that the subject position of control infinitivals was Caseless, therefore, overt noun phrases simply could not be licensed there. In the approach developed by Chomsky and Lasnik (1993), infinitivals assign a special Null Case, and only PRO is capable of having Null Case.

Finally, Control Theory governs the actual interpretation of PRO. As a first approximation, PRO's controller is the closest c-commanding noun phrase, in accordance with Rosenbaum's (1967) Minimal Distance Principle generalization (see Larson 1991 and Landau 2001, 2004 for a detailed discussion): 
(39) Minimal Distance Principle (MDP)

PRO's controller is the closest c-commanding potential antecedent

Crucially, referential PRO must have a controller, co-indexed with a c-commanding antecedent. If it does not have a controller, PRO receives an arbitrary interpretation, indicated with $\mathrm{PRO}_{\mathrm{arb}}$; we are now in a position to rework the example of nonunique control from above:

(40) It is not recommended $\left[\mathrm{PRO}_{\mathrm{arb}}\right.$ to swim here $](=(30))$

The central assumptions of this approach are summarized as follows:

(41) PRO Control assumptions

a. every argument receives exactly one theta-role (Theta Criterion)

b. PRO bears Null Case (is Caseless)

c. PRO must be bound for a referential interpretation

Within the Minimalist Program, the most successful analysis of control that retains PRO belongs to Landau $(2001 ; 2004 ; 2006 ; 2008)$. He maintains the division between raising (movement) and control (PRO in the embedded complement), but modifies the approach to PRO by eliminating Null Case (40b) ${ }^{11}$. His main idea is that PRO can bear lexical case just as any overt DP can; the crucial evidence for that claim comes from case concord in languages such as Icelandic, Hungarian and Russian, where an element associated with PRO inside the embedded clause can show its case. Crucially, the case of PRO is determined by language-specific principles, and it can be either structural as in Hungarian or German (42), or quirky as in Icelandic (43):

${ }^{11}$ See also Harley (2001) on case-marked PRO in Irish, Stenson (1989) and Sigurðsson (2004) on case-marked PRO in Icelandic. 
$(42)$

$\begin{array}{lllll}\text { Hans } & \text { hat die } & \text { Zeugen } & \text { gebeten } \\ \text { Hans } & \text { had the } & \text { witnesses } & \text { asked } \\ \text { einer } & \text { nach dem } & \text { anderen } & \text { einzutreten] } \\ \text { one.NOM } & \text { after the } & \text { other } & \text { step_in.INF }\end{array}$

'Hans asked the witnesses to step in one after the other.' (Landau 2006:152, (1d))

\begin{tabular}{llll} 
Stràkanir & \multicolumn{3}{c}{ vonast til [að $\mathrm{PRO}_{\text {ACC }}$ vanta } \\
the_boys.NOM hope & for lack.INF \\
ekki alla í & skólann] \\
not all.ACC in & the_school
\end{tabular}

'The boys hope not to be all absent from school.' (Landau 2006:152, (1a))

The other crucial component of Landau's analysis of control follows from the elimination of the Null Case. Since Case varies by language and can no longer be maintained as the critical part of the analysis of control, either empirically or theoretically, the distribution of PRO needs to be accounted for in a different way. Landau's solution is to achieve such an account using agreement: the distribution of PRO is determined by the specific values of [T] and [Agr] on the T and C heads of the embedded clause (Landau 2004, 2006). The distribution of these features is inherently tied with the distribution of independent $([+\mathrm{T},+\mathrm{Agr}])$ and dependent tense, both of which have been explored in the semantic literature. In syntax, semantic tense is indexed by the morphological feature [T] on $\mathrm{C}^{\circ}$ and $\mathrm{T}^{\circ}$ (see also chapter XXX [Zagona] for a discussion). For complement clauses, the matrix verb may impose selectional restrictions on the complementizer's [T] feature. If a matrix verb does not impose selectional restrictions on the embedded $\mathrm{C}^{\circ}$ head, that head has INDEPENDENT TENSE. If the embedded $\mathrm{C}^{\circ}$ is subject to selectional restrictions from the matrix verb, its semantic tense can either be the same as the matrix tense (ANAPHORIC TENSE) or remain partially independent of it (DEPENDENT TENSE). The latter is the case with irrealis complements, found under Hebrew finite control (Landau 2004) or in English for-complements (Bresnan 1982). Landau's proposal is that the 
scale of finiteness is tied to the value of the uninterpretable [T] and [Agr] features on the embedded $\mathrm{C}^{\circ}$ and $\mathrm{T}^{\circ}$ heads.
a. independent tense: no $[\mathrm{T}]$ on $\mathrm{C}^{\circ}(\varnothing)$
b. dependent tense: $[+\mathrm{T}]$ on $\mathrm{C}^{\circ}$
c. anaphoric tense: $[-\mathrm{T}]$ on $\mathrm{C}^{\circ}$

When the $\mathrm{C}$ and $\mathrm{T}$ heads are specified for the features $\mathrm{T}$ and Agr (thus, are $[+\mathrm{T}$, +Agr]) they always select a lexical DP; however, any other feature composition leads to the selection of PRO. The difference between a lexical DP and PRO is also encoded featurally; they differ in the value of the interpretable feature [R] (referential), with DP being $[+R]$ and PRO, [-R]. The formal implementation of these rules is as follows (with Landau's 2004, 2006 notation slightly simplified):
a. R-assignment rule For $\mathrm{X}_{[\alpha \mathrm{T}, \beta A G R]} \in\left\{\mathrm{T}^{0}, \mathrm{C}^{0}, \ldots\right\}$ :
i. $\varnothing \rightarrow \quad[+\mathrm{R}] / \mathrm{X}_{[-]}^{0}$ if $\alpha=\beta=+$
ii. $\varnothing \rightarrow[-\mathrm{R}] /$ elsewhere
b. Specifying $[\mathrm{R}]$ on DPs:
i. lexical DP, pro $\rightarrow[+\mathrm{R}]$
ii. $P R O \rightarrow[-R]$

Thus, a feature-based algorithm predicts the distribution of PRO in a variety of clausal complements. Landau himself acknowledges the stipulative nature of this algorithm (2006:162) but defends it by contending that any theory of control needs stipulative mechanisms in some of its components, be that Case or associations of functional heads with particular features required in the Minimalist Program. 


\subsection{Raising to object}

The raising to object construction has probably received the most attention in the theoretical literature, with two competing analyses on the market: Exceptional Case Marking (ECM) and true raising.

According to the ECM account (Chomsky 1981), the "raised" object is never part of the main clause: it is syntactically and semantically in the embedded clause throughout the derivation, thus:

(46) Kim expects [vр expects [vр expects] [тр Pat to offer help]]

However, the raising predicate in the main clause has an exceptional ability to case mark this embedded argument (hence exceptional case marking); this ECM ability is specified on the relevant verbs in the lexicon. The main objections to this account for English have to do with the incorrect predictions it makes with respect to word order (cf. examples (13a, b) above). In addition, there is a difference in c-command between the sentences that involve "raising", however understood, and their counterparts in which the DP in question is without doubt inside the embedded clause. To illustrate this difference, consider the following examples:

(47) a. The DA proved none of these defendants to be guilty during any of the trials

b. *The DA proved that none of these defendants was guilty during any of the trials

In (47a), the negative polarity item any is licensed by the c-commanding expression none of these defendants; NPI licensing is clause-bound, which supports the idea that the negated expression is clausemates with the NPI. In (47b), where the negative phrase is clearly enclosed within the embedded clause, NPI licensing is impossible (cf. Lasnik and Saito 1991, Runner 1998). Such a difference in licensing presents 
another formidable obstacle to the idea that the accusative object remains inside the embedded complement throughout the derivation.

Although ECM is hardly ever used to account for subject-to-object raising in English, new versions of the ECM account have been proposed for Algonquian (Bruening 2001) and some Austronesian languages (Davies and Dubinsky 2004).

In the alternative to ECM, which we will refer to as the true raising analysis, ${ }^{12}$ the subject of the embedded clause undergoes overt raising out of that clause and takes the object position of the matrix verb. This account maintains that the "raised" object is the subject of the embedded clause at D-structure (or at the point of first Merge), hence also at LF. Its presence in the lower clause allows for its interaction with that clause's material, reconstruction and binding. On the other hand, the analysis maintains that the subject of the embedded clause actually raises into the matrix clause-because of that, it can interact with the material of the higher clause, which accounts for the examples such as $(13 a, b)$ that remain problematic for the ECM analysis.

However, the true raising to object analysis runs into problems with respect to extraction facts, noted in $(14 \mathrm{a}, \mathrm{b})$ above-such sentences, where subextraction would target a subject island, are explained away under the ECM account. The following observations can be made with respect to this problem. First, the judgments on the offending examples are far from crisp, and it may well be that the problem is not categorical but just has to do with the overall complexity of the structures under consideration. If so, this is no longer a syntactic issue. But assuming that the judgments are robust, there are two possible solutions proposed by researchers: the CED account and the subjacency account.

Under the CED, or rather neo-CED account (Nunes and Uriagereka 2000, Bošković 2001, 2008, Stepanov 2001, 2007), the key idea is that phrases which have undergone movement are frozen for further extraction, in keeping with the

12 The earliest version of the true raising analysis belongs to Rosenbaum (1967) and was further developed in Postal (1974). In later work, it was defended by Authier (1991), Johnson (1991), Koizumi (1995), Runner (1998, 2006), a.o. 
standard freezing accounts (Wexler \& Culicover 1980, Rizzi 2006). The modification pursued by proponents of the neo-CED approach is that subjects always undergo such movement whereas objects do not. This explains why subjects that have been raised to the object position are frozen for extraction. However, most standard accounts of phrase structure also include objects moving outside of the VP, for instance, for Case, and this creates a further complication unresolved by the neoCED account.

Under the subjacency account (Davies and Dubinsky 2003), the crucial difference between subjects raised to object position and regular objects is in their category: regular objects can be NPs, but subjects that raise to the object position have to be DPs. As independent evidence for the difference between DPs and NPs, DPs are typically islands for movement (Longobardi 1994, 2005; Giorgi and Longobardi 1991), whereas NPs are transparent. This contrast is called upon to explain the differences in extraction. The question, of course, is what this would follow from. A possible explanation may come from the interface between syntax and information structure. ${ }^{13}$ For the case of subjects in Spec,TP, the answer could follow from the conception of that position as an A-bar, topic position. Since topics must be referential (Gundel 1974/1989, Reinhart 1982, among many others), this in turn means that they must be DPs. For the accusative subject of ECM constructions (for which it isn't clear that it is ever in a Spec,TP position), the account would have to be different: it would likely capitalize on the fact that Object Shift has information-structural effects similar to movement to Spec,TP, in particular, topicality (cf. Diesing 1996, Neeleman and Reinhart 1998, Erteschik-Shir 2007: ch. 3, a.o.). Then what subjects in the structural subject position and in the Object Shift position have in common is that they end up in positions that give rise to a topic reading, which is only available for DPs; objects, while allowed to undergo Object Shift, aren't generally forced to undergo it, so they are different from ECM-subjects in not being required to be full DPs.

13 I would like to thank Marcel den Dikken for pointing out this possibility to me. 


\subsection{Raising and Control as movement}

So far, the approaches reviewed here distinguish between raising and control, assigning them very different derivations and silent elements: raising verbs take a TP complement and involve a trace of movement, control verbs take a CP and have a special lexical item, PRO, whose behavior is determined by a number of syntactic principles outlined above. However, with the advent of the Minimalist program, one of the explicit goals of was to scrutinize the various underlying tenets of the Principles and Parameters theory and retain only those that seem truly indispensable.

Three developments in particular played a role in the change of analytical approaches to raising and control: the reconceptualization of movement as copying and deletion (internal merge), already discussed above; the reformulation of the Theta Criterion (an argument must be assigned at least one $\theta$-role under Full Interpretation, and an argument may be assigned more than one $\theta$-role), ${ }^{14}$ and the abandonment of Null Case. Altogether they effectively allow syntactic theory to dispense with PRO, which has long been considered stipulative (Hornstein 1999). The push is to achieve its effects with independently needed mechanisms.

Adopting these assumptions leads to a relatively radical reconceptualization of Control (O’Neill 1995, Hornstein 1999, Manzini and Roussou 2000). The Control relation can be derived via A-movement. The analysis thus unifies Raising and Control, which now differ minimally in whether or not the higher predicates assign a $\theta$-role to the raised NP. On Hornstein's analysis, a Control structure is derived in the following manner (irrelevant details omitted):

(48) [TP the police [VP tried [TP the police $_{\mathrm{i}}$ to[VP uphold the rules]]]]

In the lower subject position, the NP the police is assigned the agent $\theta$-role of uphold. It then raises to the higher subject position and is assigned the agent $\theta$-role of try.

14 See Brody 1993, Bošković 1994, Chomsky 1995. 
The driving forces behind the movement are the need to have $\theta$-roles assigned and the Extended Projection Principle.

This approach has several conceptual advantages over the Principles and Parameters analysis: Most obviously, it eliminates PRO and Null Case. It also eliminates the need for Control Theory and the Minimal Distance Principle to specify PRO's controller. Instead, the locality effects of the Minimal Distance Principle derive from well-known constraints on the locality of A-movement (Rizzi 1990).

One of the strongest arguments in favor of the movement approach to control is empirical; it comes from the phenomenon of backward (inverse) control. Under inverse control, the lower (embedded) member of the control chain is spelled out and the higher constituent is not expressed, thus, using a schematic representation: ${ }^{15}$

(49) $\mathrm{DP}_{\mathrm{i}} \quad$ Control Predicate $\left[\mathrm{cP} \mathrm{DP}_{\mathrm{i}} \ldots\right.$ Infinitive]

To illustrate this phenomenon, consider the following pair of sentences from the Austronesian language Malagasy (Potsdam 2009): ${ }^{16}$

$\begin{array}{lllll}\text { a. inona no } & \text { naneren' } & \text { i Paoly } & \text { azy } & \text { [ho atao _i }{ }_{i} \text { ? } \\ \text { what FOC } & \text { force.cT } & \text { Paul } & \text { 3SG.ACC do.TT } \\ \text { b. inona no } & \text { naneren' } & \text { i Paoly __i } & \text { [ho atao-nyi]? } \\ \text { what Foc } & \text { force.cT } & \text { Paul } & \text { do.TT-3SG } \\ \text { 'What did Paul force him/her to do?' } & \end{array}$

The two sentences are truth conditionally equivalent and can be shown to represent obligatory control. In (48a), the overt element of the control chain is pronounced in

15 Backward subject control has been attested in Tsez (Polinsky and Potsdam 2002), Jakaltec (Craig 1974), Greek and Romanian (Alexiadou et al. 2010). See Fukuda (2008) for an overview.

16 The glosses are slightly modified compared to the original document. 
the matrix clause, and in (48b), in the embedded clause (the silent members of the control chain are indicated by co-indexed gap symbols). However, quantifier float, extraction facts, and Condition B effects all point to the presence of a silent copy of the third singular (he/she) in the matrix clause in (48b), thus (unnecessary details of the derivation are omitted and English words are used to represent the Malagasy data):

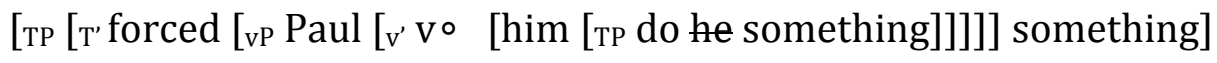

$$
\begin{aligned}
& \text { [ACC }] \text { [NOM] } \\
& \theta_{\text {force }} \quad \theta_{\text {do }}
\end{aligned}
$$

By assumption, the control complement is a TP; the DP he starts out as the external argument of that complement clause where it checks the theta-role of the verb do and receives the nominative case (unlike English, this is a case position). The DP he then moves to the higher clause and there receives a second theta-role, that of the internal argument of force. The movement is driven by the need to satisfy this thetarole feature on the higher verb. In this position, the controller also has its case feature revalued as accusative. In both structures, (50a) and (50b), the spelled out copy has all its features valued, which accounts for the possibility of an alternation. The principle of chain reduction (Nunes 2004), which we will discuss later, is responsible for the deletion of one of the copies. The outstanding difficulty of this analysis is in the multiple case checking, which, however, is a broader problem.

The Malagasy data are particularly compelling because Malagasy is not a prodrop language. On the side of a null pronominal, one might entertain the possibility that the structure of (50b) is something like (52), and condition $\mathrm{C}$ is either circumvented due to scrambling (see Cormack and Smith 2004 for a similar proposal with respect to Korean) or is simply inoperative in Malagasy. However, even if one were to try to work around condition $C$, they would run into the empirical problem that there is no evidence of object pro-drop elsewhere in Malagasy. 


\begin{tabular}{|c|c|c|c|c|}
\hline inona & no & naneren' & i Paoly $p r o_{i}$ & [ho atao-ny $]]$ \\
\hline what & FOC & force.cT & Paul 3sG.ACC & do.TT-3sG \\
\hline
\end{tabular}

Turning now to the PRO-based analysis of backward control, we see that it is fraught with problems because PRO is not c-commanded by its antecedent and cannot be licensed (or has to have an arbitrary interpretation, which is contrary to fact). The movement analysis of control, which treats the two elements as parts of a movement chain, has no problem with such a structure. The choice of a particular copy for deletion may be determined by language specific properties or may be optional if both copies have all their features checked (Potsdam 2009). In addition to backward control, there is also initial cross-linguistic evidence for backward raising (in Northwest Caucasian, see Polinsky and Potsdam 2006, Potsdam and Polinsky 2012; and in Arabic, Haddad 2010), which reiterates the similarities between the two structures. However, the issue of copy deletion/retention is still very much an open one, and it remains to be seen if the constraints on such deletion can avoid the risk of over-generation. Even if the choice of a copy for deletion allows for some arbitrariness, one would need to explain why it is usually the lower copy that gets deleted.

While the unification of control and raising under a movement analysis is supported by inverse structures, this analysis still needs to overcome a number of empirical and theoretical challenges, and we will now turn to some of those, namely arbitrary PRO, adjunct control, and control into nominals.

Under the movement analysis of control, a special analysis is needed for cases which involve arbitrary PRO, as in (29) above. Their analysis is achieved by appealing to the difference between movement and pronominalization; the key idea is that only obligatory (unique) control involves movement, whereas arbitrary control is non-obligatory and involves pronominalization. Thus:

(53) a. We decided [we to swim here] Obligatory control (OC), A-movement 
b. It is not recommended [pro to swim here] Non-obligatory control (NOC), pronominalization

On the conceptual level, this distinction is motivated by the independent evidence that both pronominalization and movement are needed in grammar. Further motivation for this distinction comes from the fact that obligatory and nonobligatory control show recurrent principled differences summarized below:

(54) properties of OC versus NOC
a. unique controller
b. strict reading under ellipsis
yes no
c. paraphrasable with a pronoun
no yes
d. allows a non-local antecedent
no yes
e. allows a non-c-commanding antecedent
no yes
f. allows for partial control
no yes
no yes

OC NOC

To illustrate with (54f), obligatory control does not permit partial control (55a), ${ }^{17}$ whereas non-obligatory control does (55b); the contrast between (55a) and (55b) also shows that non-obligatory control can have a non-c-commanding antecedent (54e):

17 For a detailed discussion of partial control, see Landau (2001: ch. 2); his claim is that partial control can be reduced to obligatory control with a PRO. A large part of the controversy surrounding partial control has to do with the empirical data which vary significantly across speakers. This is not entirely surprising given that partial control examples usually require some contextual setting (Landau 2001:27; Jackendoff and Culicover 2003) but the full range of empirical data representing partial control is not yet clear. 
(55)
a. *Mary's professor decided to apply together for a grant] b. Mary's professor wondered whether [pro to apply together for a grant]

However, while the movement theory of control treats these differences as stemming from the syntax of the two structures, a more semantically-driven approach (e.g. Jackendoff and Culicover 2003) accounts for them in non-syntactic terms. The idea behind Jackendoff and Culicover's proposal is that once more finegrained semantic distinctions among control predicates are introduced, the possibility of exhaustive vs. partial control would follow from the lexical interpretation of the relevant predicates.

Next, the movement analysis of control also needs to account for control into adjunct clauses. Such clauses always show subject control, cf.:

(56) $\operatorname{Kim}_{\mathrm{i}}\left[\mathrm{vp}\right.$ interviewed the applicants $\mathrm{s}_{\mathrm{j}}$ [cP before __i hiring them $\left.\mathrm{j}_{\mathrm{j}}\right]$ ]

Subject control into such adjunct clauses is predicted under the Minimal Distance Principle (see (39) above) because the adjunct clause is outside the VP and closer to the subject. However, in keeping with the minimalist assumptions, the adjunct clause is inside the VP, which seems to make an incorrect prediction that the controller should be the object. In addition, adjunct control is a problem for the movement analysis of control on account of the fact that it would have to involve movement out of an adjunct, in apparent violation of the CED.

Adjunct control has received a number of analyses within generative grammar, for example, Kawasaki (1993), who considers most of adjunct clauses to be PPs with a CP complement. Building on Borer (1989), Kawasaki proposes that such control structures always involve pro as a subordinate subject. This empty category is licensed by non-finite $\mathrm{T}^{0}$ inside the $\mathrm{CP}$ adjunct, and a functional head Agr identifies its content. If $\mathrm{C}^{0}$ is empty, Agr raises to $\mathrm{CP}$ and inherits the phi-features of an antecedent. These phi-features are later copied onto pro. For example, in (57), 
anaphoric Agr raises to $\mathrm{C}^{0}$ leaving a trace behind. It inherits the phi-features of John and copies them onto pro.

(57) [CP [IP John $n_{\mathrm{i}}$ felt old [Ppafter [CP Agri [IP $_{\text {pro }} \mathrm{t}_{\mathrm{i}}$ seeing himself $f_{\mathrm{i}}$ in the mirror ]]]]

In sentences like (58) and (59), on the other hand, Agr cannot be co-indexed with a c-commanding antecedent. Here, Agr is [+Topic Oriented], referring to a noncommanding antecedent, an NP that is mentioned or implied earlier in discourse.

(58) Suddenly the pirates showed up from behind the rocks. [Pp After [cP $\mathrm{Agr}_{\mathrm{i}}$ [IP pro $_{\mathrm{i}}$ robbing the passengers]]], the ship was sunk.

(59) [Pp After [ CP Agr $_{\text {[ [IP }}$ pro pitching the tents]]], darkness fell quickly (adopted from Kawasaki 1993: 172-174 (23a) and (24))

Williams (1992) divides adjunct control into two types: logophoric and predicative. In logophoric adjunct control, the controller of the unpronounced subject in the adjunct is implicit, probably mentioned earlier in discourse, as in (58). Predicative adjunct control, on the other hand, involves a grammatical controller. The adjunct in such structures is an unsaturated predicate (with an open subject position) that may be predicated of the subject in the matrix clause. That means that sentence (60a) has the structure as in (60b), where co-indexation between the adjunct and the matrix subject stands for predication. This analysis is also adopted by Landau (2001: 176-178; 2007: 304).

(60) a. Tom escaped after kissing Mary.

b. Tom ${ }_{i}$ escaped [after _ _i kissing Mary] $\mathrm{i}$.

Thus, earlier analyses of adjunct control treat all such cases, or at least a subset thereof as non-obligatory control. Within the movement approach to adjunct control, the proposal is to assimilate adjunct control into obligatory control and still 
to apply movement. This entails a reconsideration of some conceptions of movement. The key mechanism employed in this approach is that of sideward movement (Nunes 2004). Movement is a compositional process that can be broken into the operations of Copy, Merge, Form Chain, and Chain Reduction. In addition, Nunes claims that the output of movement has to be subject to the Linear Correspondence Axiom (LCA: Kayne 1994). The LCA is responsible for the ordering of elements spelled out at PF. Movement can be sideward in that a copied element can merge with another phrase marker, different from the one where it originates. Crucially, on this approach, the two copies no longer have to be in a c-command relation, so the above problem with the MDP is overcome. ${ }^{18}$ Haddad (2009a, b; 2011) provides a careful application of the general principles of sideward movement to adjunct control in Dravidian and Assamese. In this work, he shows that sideward movement correctly derives three types of adjunct control: forward adjunct control, backward adjunct control, and copy control.

The movement analysis of control would also appeal to sideward movement for the analysis of control by objects of prepositions: ${ }^{19}$

(61) John prayed [pp to Athena] to take care of herself/*himself (Culicover and Jackendoff 2001:509, ex. (47b))

(62) Kennedy's challenge [pp to NASA] to put a man on the moon by 1970 (Sichel 2010, ex. (35a))

(63) It is requested [Pp of you] to leave your bags in a locker

18 De Vries 2009 develops Nunes' ideas further and proceeds to unify regular and sideward movement as different instances of remerge.

${ }^{19}$ Control into nominals has been a long-standing problem for all control theories; in recent work, Sichel (2010) has argued that a number of empirical facts about control into nominals are related to the syntax and semantics of nominals themselves and therefore, some properties of derived nominals may be irrelevant for the typology of control. 
Finally, the movement analysis of control plays down the principled differences between control and raising discussed in section 1. In addition to reconstruction, nominalizations, and interaction with tough-movement mentioned above, there is also a significant developmental difference: children learn control structures earlier and with more ease than they learn raising (Hirsch and Wexler 2007), which is unexpected if both phenomena have the same syntax. In the discussion of the movement theory of control it is important to bear in mind, however, that it is a movement theory of control and not a raising theory of control (Boeckx and Hornstein 2010). Although this theory makes control similar to raising, it does not necessarily identify the two phenomena. While raising (in the familiar sense of the term) involves movement to a non-theta position, "control" involves movement into a theta-position. The literature arguing against the movement theory of control has often fallen prey to the temptation to think that this theory identifies raising as control.

Overall, the decision whether to pursue a unified analysis of raising and control or to keep them separate has been the subject of lively debate in generative grammar. $^{20}$

\section{Lexicalist approaches to raising and control}

In unification-based theories (Lexical Functional Grammar or LFG, and Head-Driven Phrase Structure Grammar or HPSG), raising and control are minimally different in whether or not the matrix predicate imposes selectional restrictions on the functional controller argument. Structure sharing is a major mechanism used for constraining the range of structures generated under control and raising verbs. Structure sharing serves as a kind of co-indexing that means an entire syntactic item

\footnotetext{
20 The interested reader should consult Landau (2003, 2006, 2008), Boeckx and Hornstein (2003, 2004, 2006a, b, 2010), Kiss (2006), and Bobaljik and Landau (2009) for a lively debate between the PRO-camp and the control-as-movement camp.
} 
is identical to some other item indexed ("tagged") the same way. LFG and HPSG share the following critical assumptions concerning Raising and Control:

(64) a. the relation of Raising and Control is specified lexically b. the two members of the referential dependency are represented by one syntactic entity

c. this syntactic entity is identified with the subject of the complement clause

d. the identity of controller and controlee is established in argument structure

e. the embedded clause is an infinitival VP (XCOMP in LFG)

In LFG (Bresnan 2001, Falk 2001), obligatory control is accounted for in terms of the so-called functional control or functional predication relation (anaphoric control, which roughly corresponds to non-obligatory control above, has different properties). A control predicate takes a thematic subject and a VP-type embedded construction (ХсомР) as its argument. For instance, a lexical entry for try will be partially represented as:

$$
\text { try: } \quad(\uparrow \mathrm{PRED})={ }^{\prime} \operatorname{try}\langle(\uparrow \text { SUBJ })(\uparrow \mathrm{XCOMP})\rangle
$$

A crucial assumption about the embedded predicate is that it does not have an overt subject (hence the characterization of this embedding as an open function). Functional Control serves to link the unfilled subject position of the open function (хсомР) and the subject of the matrix predicate; this linking is defined in the lexicon (Bresnan 1982, 2000, Zaenen and Engdahl 1994) by stating that the subject of the embedded predicate is also the subject of the matrix verb:

(66) $\quad$ try: $\quad(\uparrow$ PRED $)={ }^{\operatorname{try}}\langle(\uparrow \mathrm{SUBJ})(\uparrow \mathrm{XCOMP})\rangle$

$$
(\uparrow \text { SUBJ })=(\uparrow \text { XCOMP SUBJ })
$$


Another crucial assumption is that the functional controller must f-command ${ }^{21}$ the controlee, therefore it must be less deeply embedded in the functional structure. This indicates that LFG predicts Forward but not Backward Control because Backward Control would require that the f-command assumption be abandoned or modified. In modifying the theory, Sells (2006) proposes to accommodate backward (inverse) relationships by introducing the notion of subsumption, which should replace equality used otherwise to account for functional control.

\section{(67) Subsumption}

a. SUBJ $\subseteq$ XCOMP SUBJ (information only flows down from subject; whatever information subject has in the upper clause, it also has in the embedded constituent but not vice versa)

b. SUBJ $\sqsupseteq$ хСОмP SUBJ (information only flows up to subject; whatever information subject has in the embedded clause, it also has in the upper constituent but not vice versa)

Under subsumption, the direction of structure sharing can be reversed, which would allow for backward control and raising. The direction is dependent on c-structure, which in turn allows for both possibilities documented in a given language. The restrictions on subsumption may be language specific and should be provided as part of the lexical information of a given verb. The overall result is welcome in that it captures the relevant empirical facts; however, it remains to be seen if this analysis can avoid over-generation. It is also not clear how to connect the availability of backward patterns noted in the literature with other structural properties of

\footnotetext{
${ }^{21} \mathrm{f}$-command in LFG is a relationship which determines asymmetric binding from one element to another. It is roughly comparable to c-command in the Principles and Parameters framework and Minimalist Program and corresponds to ocommand in HPSG.
} 
languages such as word order or headedness (see Polinsky and Potsdam 2006 for a discussion).

In HPSG, raising and control remain more apart-raising is treated as true unification, while control is achieved by the identity of indices. In neither structure is there a structural position in the embedded clause containing a trace or a pro; recall that the embedded clause is just the infinitival VP.

Sag, Wasow and Bender (2003) and Runner (2006) show the advantages of handling object raising and control in HPSG terms. To account for raising to object and object control constructions in a uniform way, they propose general constraints on the verbs which license raising to object and object control constructions; these constraints are again specified in the lexicon:

$$
\text { object-raising-verb-lexeme: ARG-ST < NP, (1), [SYN [VAL[SPR < (1) }>\text { ]] }>
$$
object-control-verb-lexeme: ARG-ST<NP, $\mathrm{NP}_{\mathrm{i}},\left[\mathrm{SYN}\left[\mathrm{VAL}\left[\mathrm{SPR}<\mathrm{NP}_{\mathrm{i}}>\right]\right]\right]>$

A raising to object verb such as believe or expect will be typed as an object raising verb lexeme. The constraint in (68) places restrictions on what items appear in the argument structure (ARG-ST) of a lexeme of that type. This constraint states that the argument structure of this class of lexemes contains three phrases. The first is a DP (NP). The second item in the argument structure is indicated by the tag (1). Another tag of the same nature is on the third argument on this type's argument structure; thus, the second argument and the specifier (SPR) of its third argument are structure-shared. Separate independently motivated constraints in the grammar restrict the category of the second phrase to an NP.

An object control verb like 'persuade' will be typed as an object control verb lexeme and will be subject to the constraint in (69). It is identical to the constraint on object raising verbs in (68) except that the item in the argument structure is an NP co-indexed with rather than structure-shared with the specifier of the third argument. In contrast to structure-sharing (tagging), co-indexation proper in HPSG indicates intended reference (for instance, in binding as well as in control). 
Thus, on the HPSG account, the sentence structures for object raising and object control look identical:

(70) Kim [vp expected Pat [vp to run the race]]

(71) Kim [vp persuaded Pat [vp to run the race]]

The main difference resides in the different relationships between the object of the matrix clause (Pat) and the lexical subject of the embedded verb: in (70) they are the same NP, and in (71), they are co-indexed, which implies a looser relationship due to the fact that they both have their own thematic roles.

Within the framework of Cognitive Grammar (Langacker 1995), raising and control are treated in a similar way: despite apparent differences in the implementation and technical aspects, Cognitive Grammar shares with LFG and HPSG the idea of function sharing and of lexical specification. As in LFG, Cognitive Grammar does not divide raising and control into separate phenomena in need of different analyses; instead, they are treated as part of a continuum-this is called for to explain situations where one and the same verb can have both control and raising uses, as is the case with many aspectual predicates (cf. Perlmutter 1970; Davies and Dubinsky 2004), cf.:

(72) a. More progress can begin to be made in this direction b. The soldiers began to dismantle the fort

Cognitive Grammar identifies the relationship between the sentences which have a referential dependency (73a), (74a) and their "non-raised" counterparts (73b), (74b) without a referential dependency as that of partial synonymy and emphasizes principled differences between them.

(73) a. Don is likely to leave

b. We expect Don to leave 
(74) a. That Don will leave is likely

b. We expect that Don will leave

Simplifying things somewhat, the choice of a "raised" or "non-raised" version depends on semantics and pragmatics, in particular, on information structure. If the focus of the utterance is on the event denoted by the entire sentence, a non-raised sentence is more likely, whereas if the subject of the embedded clause is informationally prominent then the "raised" version is chosen.

\section{Raising, control, and the typology of empty categories}

As this overview of raising and control phenomena has shown, there are a number of approaches to the structures outlined in section 1. Since the work on raising and control has been at the forefront of linguistic theorizing for decades, the literature is full of rich empirical evidence that needs to be accounted for in theories of raising and control. Not only do these data raise questions concerning the appropriateness of a particular theory and the prevalence of syntax or semantics, they also have a bearing on the inventory of silent categories in modern syntax.

The range of empirical facts considered here allows at least some theories to recognize the following inventory of silent categories:

(75) silent elements in control and raising structures
a. pro (null pronominal)
b. PRO
c. trace of A-movement (movement to an argument position)

For completeness, we should also mention the variable (A-bar bound trace), which plays an important role in the overall typology of silent categories but is not relevant to the issues discussed in this chapter.

The distribution of the null pronominal is well regulated by the principles of Binding Theory, Principle B in particular. As shown above, the null pronominal is 
mostly observed in cases where there is no unique controller-some theories account for it as non-obligatory control (NOC).

The distribution of PRO was subject of the PRO-Theorem in the Principles and Parameters framework. However, after some of the fundamental principles of generative syntax were revised in the Minimalist Program, the distribution of PRO can no longer be explained by the same rules. The most articulated account of PRO's distribution can be found in the work by Landau (see section 2.1 above). The main conception behind the distribution of PRO now has to do with the referential status of DPs as linked to the features T and Agr on the higher functional heads of the clause, $\mathrm{T}$ and $\mathrm{C}$.

Finally, the distribution of NP-movement in argument positions is regulated by the principles of relativized minimality and locality as described in chapters XXX.

A fundamental question concerning the distribution of silent elements has to do with the nature of the relationship between the constituent that has independent reference and the silent (or partially spelled out) constituent whose reference is dependent on the former. There are essentially two ways of achieving that: predication and binding.

Under the predication approach to control (which can also be extended to raising), there is a dependency between the element that has full referential content (controller) and the embedded complement, which represents a predicate. Thus, (76) below is interpreted as meaning "In all worlds where the police's intentions hold, the police have the property of staying calm".

(76) The police intended to stay calm $((=17))$

Predicational approaches to control were initially proposed in semantic analyses (Bach 1979, 1982, Chierchia 1984, Dowty 1985).

In syntax, the predicational approach to control stems from Williams' work (Williams 1980; 1985; 1987), which presents a particularly careful examination of predication and argues that referential dependencies involved in control are a subset of the more general class of predication relations. Predication is established 
at a special grammatical level (Predicate Structure), which means that it is partially independent of the actual projected arguments and can potentially involve implicit arguments. The crucial requirements on predication are twofold: the logical subject of the predication relation has to be external to the predicate, and the relation itself has to be local. Locality is implemented by the requirement that the DP predicated of must be in a mutual c-command relation with (a) the predicate or (b) another predicate that immediately contains it, which lets in the matrix VP. This disjunctive formulation allows us to account for adjunct control (c-command relation between the subject and the predicate) and complement control (sub-requirement (b)).

The predication relation thus crucially depends on the presence of an external argument, which serves as a variable vertically bound by its maximal projection (Williams refers to that as a kind of lambda-abstraction). For his approach, it is not critical that the role be realized as a syntactic node in the phrase structure-the only crucial requirement is that such a role be understood as present and can act as a bound variable. While some researchers criticize this approach as too general or weak (see Landau to appear), it provides an important foundation for the establishment of predication relations.

The binding approach to control treats the silent element in the complement clause as a null anaphor. The locality of control is achieved by limiting the binding domain to the clause immediately dominating the embedded complement clause. Such an analysis can easily account for obligatory control and, as long as the adjunct clause is adjoined low, for adjunct control as well. A major challenge to such an approach comes from non-obligatory control where this binding condition is violated. To preserve the overall conception of control as binding, Manzini (1983, 1986) proposed that an anaphor without a governing category be bound in its domain-governing category. This entails that a silent element without a binding domain is exempt from binding. Manzini's binding approach works in the following manner:

(77) a. complement clauses always have a binding domain, the matrix clause (hence, these clauses instantiate obligatory control) 
b. subject clauses lack a binding domain because the clause immediately dominating them has no accessible subject (hence, non-obligatory control)

Other binding approaches to control have have focused on non-obligatory control where the silent element is analyzed as a pronoun (Bouchard 1984, Koster 1984, Hornstein 2003).

Both approaches, viz. predication and binding, successfully account for the bulk of control phenomena and can be extended to raising. However, they face problems with adjunct control (especially if the adjunct clause is not in the VP). In addition, the binding approach to control requires a substantial reconsideration of independently established binding generalizations. Lebeaux (1984) presents an interesting attempt to combine the advantages of both approaches without a more significant readjustment of the theoretical machinery involved.

\section{Beyond the scope of this chapter}

This chapter has presented the empirical foundations of raising and control constructions and has outlined major theoretical approaches to these constructions, with a focus on syntactic analyses. The debate between the syntactic and semantic approach to raising and control has been going on for decades, and although each side may claim victory, their true success has to do with uncovering a broader range of natural language phenomena that need to be accounted for by any theory of raising and control. The range of phenomena that a successful theory of raising and control has to account for is much broader. For instance, an important phenomenon that we have not discussed here is that of copy raising (78) and its rarer counterpart, copy control:22

(78) a. There looks like there could be a different solution

b. Richard seems like he is in trouble

${ }^{22}$ See Polinsky and Potsdam (2006) for some discussion of copy control. 
Under copy raising, first introduced on the linguistic scene by Rogers (1974), both elements of the dependency are pronounced or partially pronounced, and the crucial question, which still evokes significant debate, has to do with the possibility of analyzing this construction as true raising or as a completely different phenomenon (see Potsdam and Runner 2001, Asudeh and Toivonen to appear, Landau 2010, Haddad 2009a, and further references therein).

Another important question has to do with the relation between raising and tough-movement illustrated in (79):

(79) This professor is tough to please

The initial analysis of this construction, proposed by Rosenbaum (1967), identified it as an A-movement operation, a type of object-to-subject raising. The raising analysis of tough-movement was also developed by Brody (1993) and Hartman (2009); all these analyses emphasize that the matrix predicate does not assign an external theta-role, which is typical of raising. Other researchers however have pointed out the presence of A-bar effects in tough-movement (Chomsky 1977, 1981; Rezac 2006; Hicks 2009 and references therein). The debate on tough-movement and its place in the family of raising and control constructions is still ongoing.

Another important area of inquiry that has been particularly productive lately is that into finite control-a control structure where the embedded complement is finite. Compare subject and object finite control in Persian, with the finite predicate of the embedded clause appearing in the subjunctive (see Hashemipour 1989, Ghomeshi 2001, Karimi 2008 for details):

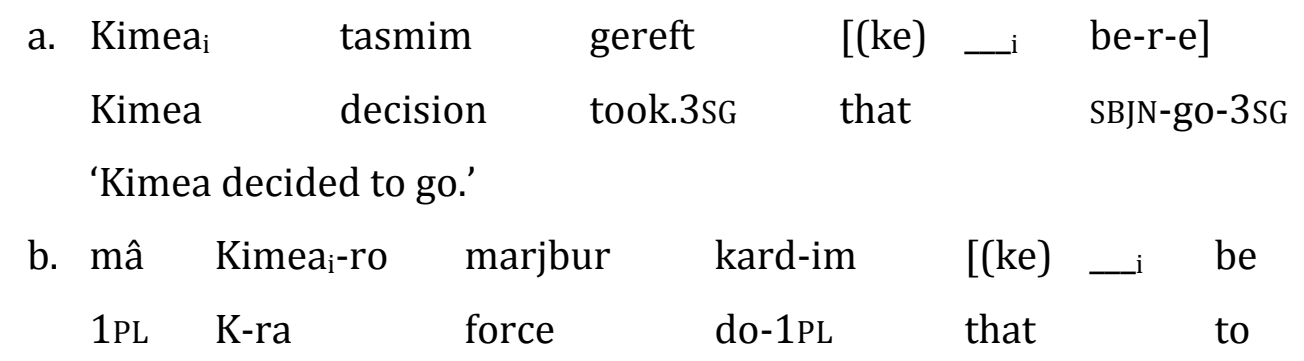




$$
\begin{array}{ll}
\text { sinamâ } & \text { be-r-e] } \\
\text { movies } & \text { SBJN-go-3SG }
\end{array}
$$

'We forced Kimea to go to the movies.'

In the Principles and Parameters framework, which had the PRO-Theorem, an account of finite control was quite challenging. With the development of other approaches, syntactic and lexicalist, and with the dissociation between PRO and Case, finite control has emerged as an interesting possibility which may or may not require a unified account. Aside from Persian, finite control has been documented in Greek (Terzi 1992) and other Balkan languages (see Landau 2004 and references therein), where it is motivated by language-specific properties since Balkan languages lack infinitives, in Arabic (Haddad 2010), and in Malagasy (Potsdam and Polinsky 2007).

Some other areas of inquiry include (i) the phenomenon of partial control just briefly touched upon above (see Landau 2001, Stiebels 2010, Snarska 2009, Madigan 2009, among others); (ii) the special status of promise and threaten (Langacker 1995, Larson 1991, Hornstein 2003), and related to that, (iii) Visser's generalization (Visser 1973, Bresnan 1982, Bach 1980, Rudanko 1989), according to which object control structures have corresponding passives, while subject control structures do not, as shown in (81) and (82):

(81) a. Pat persuaded Kim to run the race

b. Kim was persuaded by Pat to run the race

a. Kim promised Pat to run the race

b. *Pat was promised by Kim to run the race

Within syntactic theories, the approach to raising and control has a bearing on the structure of embedded clausal complements (see the differences across frameworks concerning the size of such complements in control and raising), the inventory and nature of silent elements, and the need for a distinction between raising and control altogether. 


\section{References}

Alexiadou et al. 2010. No Objections to Backward Control. In Norbert Hornstein and Maria Polinsky (eds.). Movement theory of control, 89-117. Amsterdam: John Benjamins.

Asudeh, Ash, and Ida Toivonen. To appear. Copy raising and perception. Natural Language and Linguistic Theory.

Authier, J.-Marc. 1991. V-governed expletives, case theory, and the projection principle. Linguistic Inquiry 22: 721-740.

Bach, Emmon. 1979. Control in Montague grammar. Linguistic Inquiry 10: 515-531.

Bach, Emmon. 1982. Purpose clauses and control. In Pauline Jacobson and Geoffrey Pullum (eds.). The nature of syntactic representation, 35-57. Dordrecht: Reidel.

Baltin, Mark. 1995. Floating quantifiers, PRO, and predication. Linguistic Inquiry 26: 199-248.

Bennis, Hans. 1986. Gaps and dummies. Dordrecht: Foris.

Bobaljik, Jonathan, and Idan Landau. 2009. Icelandic control is not A-movement: The case from Case. Linguistic Inquiry 40: 113-132.

Boeckx, Cedric, and Norbert Hornstein. 2003. Reply to "Control is not movement". Linguistic Inquiry 34: 269-280.

Boeckx, Cedric, and Norbert Hornstein. 2004. Movement under control. Linguistic Inquiry 35: 431-452.

Boeckx, Cedric, and Norbert Hornstein. 2006a. Control in Icelandic and theories of control. Linguistic Inquiry 37: 591-606.

Boeckx, Cedric, and Norbert Hornstein. 2006b. The virtues of control as movement. Syntax 9: 118-130.

Boeckx, Cedric, and Norbert Hornstein. 2010. Icelandic control really is Amovement: A reply to Bobaljik and Landau. Linguistic Inquiry 41: 111-130.

Borer, Hagit. 1989. Anaphoric AGR. In Osvaldo Jaeggli and Kenneth Safir (eds.) The Null Subject Parameter, 69-109. Kluwer Academics Publishers. 
Bošković, Zeljko. 1994. D-structure, Theta-Criterion, and movement into Thetapositions. Linguistic Analysis 24: 247-286.

Bošković, Zeljko. 2001. On the nature of the syntax-phonology interface: Cliticization and related phenomena. Oxford: Elsevier.

Bošković, Zeljko. 2008. On successive-cyclic movement and the freezing effect of feature checking. In Jutta Hartmann, Veronika Hegedűs, and Henk C. van Riemsdijk (eds.). Sounds of silence: Empty elements in syntax and phonology, 195-205. Oxford-Amsterdam: Elsevier.

Bresnan, Joan. 1972. Theory of complementation in English syntax. Ph.D. Dissertation, MIT. (Published by Garland 1979).

Bresnan, Joan. 1982. Control and complementation. Linguistic Inquiry 13: 343-434. Bresnan, Joan. 2001. Lexical-Functional Syntax. Oxford: Blackwell.

Brody, Michael. 1993. $\theta$-Theory and arguments. Linguistic Inquiry 24: 1-23.

Bruening, Benjamin. 2001. Syntax at the edge: Cross-clausal phenomena and the syntax of Passamaquoddy. Ph.D. Dissertation, MIT.

Chierchia, Gennaro. 1984. Topics in the syntax and semantics of infinitives and gerunds. Ph.D. Dissertation, University of Massachussetts, Amherst.

Chomsky, Noam. 1955/1975. The logical structure of linguistic theory. MIT Humanities Library. New. York and London: Plenum Press.

Chomsky, Noam. 1973. Conditions on transformations. In Stephen Anderson and Paul Kiparsky (eds.). Festschrift for Morris Halle, 232-286. New York: Holt, Rinehart and Winston.

Chomsky, Noam. 1977. On wh-movement. In Peter Culicover, Tom Wasow, and Adrian Akmajian (eds.). Formal syntax, 77-132. New York: Academic Press. Chomsky, Noam, 1981. Lectures on Government and Binding. Dordrecht: Foris. Chomsky, Noam, 1982 Some Concepts and Consequences of the Theory of Government and Binding. Cambridge, Massachusetts: MIT Press.

Chomsky, Noam. 1995. The minimalist program. Cambridge, MA: MIT Press.

Chomsky, Noam. 2000. Minimalist Inquiries: The framework. In Roger Martin, Dan Michaels, and Juan Uriagereka (eds.). Step by Step: Essays on Minimalist Syntax in Honor of Howard Lasnik, 89-155. Cambridge, MA: MIT Press. 
Chomsky, Noam. 2008. On phases. In Robert Freidin, Carlos Otero, and Maria Luisa Zubizarreta (eds.). Foundational issues in linguistic theory. Essays in honor of Jean-Roger Vergnaud, 133-166. Cambridge, MA: The MIT Press.

Chomsky, Noam, and Howard Lasnik. 1993. The theory of Principles and Parameters. In Joachim Jacobs, Arnim von Stechow, Wolfgang Sternefeld, and Theo Vennemann (eds.). Syntax: An International Handbook of Contemporary Research. Berlin: Mouton de Gruyter [Also published in N. Chomsky, The Minimalist Program, 13-128. Cambridge, Mass.: MIT Press, 1995.]

Comrie, Bernard. 1984. Subject and object control: Syntax, semantics, pragmatics. Proceedings of the Berkeley Linguistic Society 10:450-64.

Comrie, Bernard. 1985. Reflections on subject and object control. Journal of Semantics 4: 47-65.

Cormack, Annabel, and Neil Smith. 2004. Backward control in Korean and Japanese. University College London. Working Papers in Linguistics 16: 57-83.

Craig, Colette G. 1974. A wrong-cyclical rule in Jacaltec? In Proceedings of the 10th Regional Meeting of the Chicago Linguistic Society, 103-116. Chicago Linguistic Society, University of Chicago, Chicago, Ill.

Culicover, Peter, and Ray Jackendoff. 2001. Control is not movement. Linguistic Inquiry 32: 493-511.

Culicover, Peter, and Ray Jackendoff. 2005. Simpler syntax. Oxford: Oxford University Press.

Davies, William, and Stanley Dubinsky. 2003. On extraction from NPs. Natural Language and Linguistic Theory 21: 1-37.

Davies, William, and Stanley Dubinsky. 2004. The grammar of raising and control. Malden, MA: Blackwell.

De Vries, Mark. 2009. On multidominance and linearization. Biolinguistics 3, 344403.

Diesing, Molly. 1996. Semantic variables and object shift. In Hoskuldur Thrainsson and Samuel Epstein (eds.). Studies in comparative Germanic syntax, Volume 2, 66-84. Dordrecht: Kluwer. 
Dowty, David. 1985. On recent analyses of the semantics of control. Linguistics and Philosophy 8: 291-331.

Ernst, Thomas. 2002. The syntax of adjuncts. Cambridge: Cambridge University Press.

Erteschik-Shir, Nomi. 2007. Information structure: The syntax-discourse interface. Oxford: Oxford University Press.

Falk, Yehuda. 2001. Lexical-Functional Grammar: An introduction to parallel constraint-based syntax. Stanford, CA: CSLI.

Farkas, Donka F. 1988. On obligatory control. Linguistics and Philosophy 11:27-58.

Fukuda, Shin. 2008. Backward control. Language and Linguistic Compass 2: 168-195.

Giorgi, Alessandra, and Giuseppe Longobardi. 1991. The syntax of noun phrases. Configurations, parameters, and empty categories. Cambridge: Cambridge University Press.

Gundel, Jeanette. 1974. The role of topic and comment in linguistic theory. Ph.D. Dissertation, University of Texas at Austin (published by Garland in 1989).

Haddad, Youssef A. 2009a. Copy control in Telugu. Journal of Linguistics, 45, 69-109.

Haddad, Youssef A. 2009b. Adjunct control in Telugu: Exceptions as non-exceptions. Journal of South Asian Linguistics 2: 35-51.

Haddad, Youssef A. 2010. Raising in Standard Arabic: Forward, backward, and none. Ms. University of Florida.

Haddad, Youssef A. 2011. Control into conjunctive participle clauses: The case of Assamese. Berlin: Mouton de Gruyter.

Harley, Heidi. 2001. Irish, the EPP and PRO. Ms. Department of Linguistics, University of Arizona.

Hartman, Jeremy. 2009. Intervention in Tough-constructions. Proceedings of Northeastern Linguistic Society 39: XX.

Hicks, Glyn. 2009. Tough-constructions and their derivation. Linguistic Inquiry 40: 535-566.

Hirsch, Christopher, and Kenneth Wexler. 2007. The late development of raising: What children seem to think about seem. In Stanley Dubinsky and William 
Davies (eds.). New horizons in the analysis of control and raising, 35-70. New York-Dordrecht: Springer.

Hornstein, Norbert. 1999. Movement and control. Linguistic Inquiry 30: 69-96. Hornstein, Norbert. 2001. Move! A Minimalist theory of construal: Generative syntax. United Kingdom: Blackwell.

Hornstein, Norbert. 2003. On control. In Randall Hendrick (ed.) Minimalist syntax, 681. Oxford: Blackwell.

Huang, C.-T. James. 1989. Pro-drop in Chinese: A generalized Control theory. In Oswaldo Jaeggli and Ken Safir (eds.). The null subject parameter, 185-214. Dordrecht: Kluwer.

Jackendoff, Ray. 1972. Semantic interpretation in generative grammar. Cambridge, MA: MIT Press.

Jackendoff, Ray, and Peter Culicover 2003. The semantic basis of control in English. Language 79: 517-556.

Johnson, Kyle. 1991. Object positions. Natural Language and Linguistic Theory 9: 577-636.

Karimi, Simin. 2008. Raising and control in Persian. In Simin Karimi, Donald Stilo, and Vida Samiian (eds.). Aspects of Iranian linguistics, 177-208. Newcastle upon Thyne: Cambridge Scholars.

Kawasaki, Noriko. 1993. Control and arbitrary interpretation in English. Ph.D. Dissertation, University of Massachussetts at Amherst.

Kayne, R., 1994. The antisymmetry of syntax. Cambridge, MA: MIT Press

Kiss, Tibor 2006. On the empirical viability of the movement theory of control. Ms. Bochum University.

Koizumi, Masatoshi. 1995. Phrase structure in minimalist syntax. Ph.D Dissertation, MIT, Cambdrige, Mass.

Koster, Jan. 1984. On binding and control. Linguistic Inquiry 15: 417-459.

Landau, Idan. 2001. Elements of control: Structure and meaning in infinitival constructions. Dordrecht: Kluwer.

Landau, Idan. 2003. Movement out of control. Linguistic Inquiry 34:471-498. 
Landau, Idan. 2004. The scale of finiteness and the calculus of control. Natural Language and Linguistic Theory 22, 811-877.

Landau, Idan. 2006. Severing the distribution of PRO from Case. Syntax 9: 153-170. Landau, Idan. 2007. Movement-resistant aspects of control. In William D. Davies and Stanley Dubinsky (eds.). New Horizons in the Analysis of Control and Raising, 293-325. Dordrecht: Springer.

Landau, Idan. 2008.Two routes of control: evidence from case transmission in Russian. Natural Language and Linguistic Theory 26: 877-924.

Landau, Idan. To appear. Predication vs. aboutness in copy raising. Natural Language and Linguistic Theory.

Langacker, Ronald W. 1995. Raising and transparency. Language 71: 1-62.

Larson, Richard. 1991. Promise and the theory of control. Linguistic Inquiry 21: 103139.

Lasnik, Howard, and Mamoru Saito. 1991. On the subject of infinitives. In Proceedings of the 27th Regional Meeting of the Chicago Linguistic Society, 324-343. Chicago Linguistic Society, University of Chicago, Chicago, Ill.

Lebeaux, David. 1984. Anaphoric binding and the definition of PRO. Northeastern Linguistic Society 14: 253-274.

Longobardi, Giuseppe. 1994. Reference and proper names: A theory of N-movement in syntax and Logical Form. Linguistic Inquiry 25: 609-665.

Longobardi, Giuseppe. 2005. Toward a unified grammar of reference. Zeitschrift fur Sprachwissenschaft 24, 5-44.

Madigan, Sean. 2009. Control constructions in Korean. Ph.D. Dissertation, University of Delaware.

Manzini, Rita. 1983. On control and control theory. Linguistic Inquiry 14: 421-446.

Manzini, Rita. 1986. On control and binding theory. Northeastern Linguistic Society 16: 322-337.

Manzini, Rita, and Anna Roussou. 2000. A Minimalist theory of A-movement and control. Lingua 110: 409-447.

Martin, Roger. 2001. Null Case and the distribution of PRO. Linguistic Inquiry 32: 141-166. 
Moro, Andrea. 1997. The raising of predicates: Predicative noun phrases and the theory of clause structure. Cambridge: Cambridge University Press.

Neeleman, Ad, and Tanya Reinhart. 1998. Scrambling and the PF interface. In Miriam Butt and W. Geuder (eds.). The projection of arguments, 309-353. Stanford: CSLI.

Nuñes, Jairo. 1995. The copy theory of movement and linearization of chains in the Minimalist Program. Ph.D. Dissertation, University of Maryland.

Nuñes, Jairo. 2004 Linearization of chains and sideward movement. Cambridge, MA: MIT Press.

Nuñes, Jairo, and Juan Uriagereka. 2000. Cyclicity and extraction domains. Syntax 3, 20-43.

O'Neill, James. 1995. Out of control. In Proceedings of the 25th Annual Meeting of the North East Linguistic Society, 361-371. GLSA, University of Massachusetts, Amherst.

Panther, Klaus-Uwe. 1993. Kontrollphänomene im Englischen und Deutschen aus Semantisch-pragmatisher Perspektive. Tübingen: Narr.

Perlmutter, David. 1970. The two verbs begin. In Roderick Jacobs and Peter Rosenbaum (eds.). Readings in English transformational grammar, 107-119. Waltham, MA: Blaisdell.

Petter, Marga. 1998. Getting PRO under control. The Hague: Holland Academics Graphics.

Polinsky, Maria and Eric Potsdam. 2002. Backward control. Linguistic Inquiry 33:245-282.

Polinsky, Maria and Eric Potsdam. 2006. Expanding the scope of control and raising. Syntax 9:171-192.

Postal, Paul. 1970. On coreferential complement subject deletion. Linguistic Inquiry 1: 439-500.

Postal, Paul. 1974. On Raising. Cambridge, MA: MIT Press.

Potsdam, Eric. 2009. Malagasy backward object control. Language 85: 754-784.

Potsdam, Eric, and Maria Polinsky. 2007. Missing complement subjects in Malagasy. Oceanic Linguistics 46:277-303. 
Potsdam, Eric, and Maria Polinsky. 2012. Backward raising. Syntax (to appear).

Potsdam, Eric, and Jeffrey Runner. 2001. Richard returns: Copy raising and its implications. Proceedings of the 37th Regional Meeting of the Chicago Linguistic Society, 453-468. Chicago Linguistic Society, University of Chicago, Chicago, Ill.

Reinhart, Tanya. 1982. Pragmatics and linguistics: An analysis of sentence topics. Bloomington: Indiana University Linguistics Club.

Rezac, Milan. 2006. On tough-movement. In Cedric Boeckx (ed.). Minimalist essays, 288-325. Amsterdam: John Benjamins.

Rizzi, Luigi. 1978. A restructuring rule in Italian syntax. In Samuel Jay Kayser (ed.), Recent transformational studies in European languages, 113-158. Cambridge, MA: MIT Press.

Rizzi, Luigi. 1982. Issues in Italian syntax. Dordrecht: Kluwer.

Rizzi, Luigi. 1990. Relativized minimality. Cambridge, MA: MIT Press.

Rizzi, Luigi. 2006. On the form of chains: Criterial positions and ECP effects. In Lisa Cheng and Norbert Corver (eds.). Wh-movement: Moving on, 97-134. Cambridge, MA: MIT Press.

Rosenbaum, Peter S,1967. The grammar of English predicated complement constructions. Cambridge, MA: MIT Press.

Runner, Jeffrey T. 1998. Noun phrase licensing. New York: Garland.

Runner, Jeffrey T. 2006. Lingering challenges to the Raising-to-Object and ObjectControl constructions. Syntax 9: 193-213.

Růžička , Rudolf. 1983. Remarks on control. Linguistic Inquiry 18:309-324.

Růžička, Rudolf. 1999. Control in grammar and pragmatics. A cross-linguistic study. Amsterdam: John Benjamins.

Sag, Ivan, and Pollard, Carl. 1991. An Integrated theory of Complement Control. Language 67:63-113.

Sag, Wasow and Bender, Emily. 2003. Syntatic theory: A formal introduction, $2^{\text {nd }}$ Edition. Stanford, CA: CSLI Publications.

Sells, Peter. 2006. Using subsumption rather than equality in functional control. Proceedings of the 2006 LFG Conference, University of Konstanz. 
Sichel, Ivy. 2010. Towards a typology of control in DP. In Norbert Hornstein and Maria Polinsky (eds.). Movement theory of control, 245-267. Amsterdam: John Benjamins.

Sigurðsson, Halldór. 2004. Icelandic non-nominative subjects. In Karumuri Venkata Subbarao and Peri Bhaskararao (eds.). Non-nominative subjects: Vol. 2, $137-$ 160. Amsterdam: John Benjamins.

Snarska, Anna. 2009. On certain troublemakers to partial control as Agree. University of Pennsylvania Working Papers in Linguistics 15, 1: 203-212.

Stenson, Nancy. 1989. Irish autonomous impersonals. Natural Language and Linguistic Theory 13:561-570.

Stepanov, Arthur. 2001. The end of CED? In Karine Megerdoomian and Laura A. Barel (eds.). WCCFL 20 Proceedings. Somerville, MA: Cascadilla Press.

Stepanov, Arthur. 2007. The end of CED? Minimalism and extraction domains. Syntax 10: 80-126.

Stiebels, Barbara. 2007. Towards a typology of complement control. In Barbara Stiebels (ed.), ZAS Papers in Linguistics 47. Studies in complement control, 180.

Stiebels, Barbara. 2010. Control. MS. Zentrum für allgemeine Sprachwissenschaft, Berlin.

Wegener, Heide. 1989. Kontrolle-semantish gesehen. Deutshe Sprache 3:206-228.

Wexler, Kenneth, and Peter Culicover. 1980. Formal principles of language acquisition. Cambridge, MA: MIT Press.

Williams, Edwin. 1980. Predication. Linguistic Inquiry 11: 203-238.

Williams, Edwin. 1985. PRO and subject NP. Natural Language and Linguistic Theory 3: 297-315.

Williams, Edwin. 1987. NP trace in Theta Theory. Linguistics and Philosophy 10:433447.

Williams, Edwin. 1992. Adjunct control. In Richard Larson, Sabine Iatridou, Utpal Lahiri and James Higginbotham (eds.). Control and Grammar, 297-322. Dordrecht: Kluwer. 
Wurmbrand, Susanne. 2001. Infinitives. Restructuring and clause structure. Berlin: Mouton de Gruyter.

Wurmbrand, Susanne. 2007. Infinitives are tenseless. Penn Working Papers in Linguistics 13.1: 407-420.

Zaenen, Annie, and Elisabet Engdahl. 1994. Descriptive and theoretical syntax in the lexicon. In B. T. S. Atkins and A. Zampolli (eds.). Computational approaches to the lexicon: Automating the lexicon II, 181-212. Oxford: Oxford University Press. 